\section{DE DE GRUYTER OPEN}

Przedsiębiorczość i Zarządzanie Entrepreneurship and Management University od Social Sciences Publishing House ISSN 1733-2486

Volume XVI, Issue 1, pp. 83-95

DOI 10.1515/eam-2015-0006

Dominika Korzeniowska

University of Social Sciences

\title{
Managers' Consideration about Behavioural Factors that Influence their Decision Making in Liquidity Management
}

\begin{abstract}
The paper presents selected fragment of the outcomes of qualitative research led by the author. It concerned factors influencing decision-making in liquidity management, associated with human traits (human as an acting person of such choices) both in terms of mental processes' characteristics peculiar to the entire human species (features of human mind) as well as the specific attributes of individual decisionmakers. The aim of the study was to discover how managers perceive determinants of liquidity decision-making process, basing on their professional experience, and whether in their consideration on the subject had ever appeared the determinants related to the person of the decision-maker.
\end{abstract}

Key words: behavioural economy, decision making, decision traps, liquidity.

\section{Introduction}

In recent years, interrelatedness between psychology and economics or finance seems to intensify. From scientific point of view these relation became a fact and economists are no longer entitled to ignore findings made by psychologist in the area of economics [Zaleskiewicz 2011]. However, the question is how fast and how deep these discoveries are absorbed by the real economy, i.e. the people who actually take financial decisions every day. They should be the first to benefit from this knowledge, so that they could make more effective choices in their daily work. 
Unfortunately, it seems that there is still a substantial discrepancy between what has already been discovered by the science and what practitioners actually use while making decisions. The research carried out by the author appears to prove this thesis. Hitherto, education of financiers has been conducted in the spirit of homo economicus, which means that people are fully rational, maximizing their own benefit, having unlimited cognitive abilities and the constant risk preference [Jones 1999]. Therefore, it is established on so-called normative model [Tyszka 2010]. While assessing financial standing of the enterprise and making the right choices based on that, the achievements of the classical theory of finance cannot be overestimated. However, enriching trainings for managers with contents related to psychological economy and behavioural finance would bring many benefits. Not only would managers know how to properly use the "tools" provided by the neoclassical theory of finance, but also what to pay a special attention to or what to avoid, when it comes to their way of evaluating available data, so as not to be subject to some psychological traps [Tyszka 2000]. While the newly educated managerial cadres can be somehow made to develop their knowledge of behavioural finance by including such issues into the compulsory curriculum, the managers who have already completed their basic education might not have such an opportunity. Hence, it is vital to verify if managers have ever wondered how they make their decisions, what factors they take into account in their choices and whether among these factors there are also the behavioural ones. All this is to be able to provide them with tailored educational offer that would broaden their perspective about decisions-making process with the output of behavioural economics and behavioural finance.

The paper presents a fragment of outcomes relating to qualitative research, led by the author. A subject of the study were factors influencing decision-making in liquidity management, associated with human traits (human as an acting person of such choices) both in terms of mental processes' characteristics peculiar to the entire human species (features of human mind) as well as the specific attributes of individual decision-makers. This study was an attempt to discover how managers perceive determinants of decision-making process concerning liquidity management for the company they worked for, and whether in their consideration on the subject had ever appeared the determinants related to the person of the decision-maker, including so-called "decision traps" [Korzeniowska 2011], in other words "inadequacies or errors in assessing, appearing due to various reasons" [Tyszka 2000]. The findings about which traps occurred during the liquidity-related decision-making process and about the respondents' awareness of the 
existence of such phenomena as well as their impact on the final decision's quality, were presented in other publications of the author [Korzeniowska 2013].

\section{Method}

This paper presents findings giving response to the following research questions:

1. Had managers ever in the past been considering how they took decisions related to liquidity, how the process of making such decisions looked like and whether in their decision-making they had ever taken into account the impact of human traits (retrospective approach)?

2. What were the respondents' beliefs about determinants of liquidity-related decision-making process presented in the course of the interview ('current' approach, induced reflection)?

It needs to be underlined that in both above mentioned cases, particularly important was to select such respondents' statements that presented characteristics associated with the person of decision maker.

The research was done by means of qualitative method and a technique was in-depth interview.. According to the methodological recommendations on qualitative methods, interviewees were diversified in terms of age and gender. There were people who had economic background (education, courses, trainings), with a minimum of 2-year work experience, who made decisions related to liquidity of the company (CFO, chairman, chief accountant etc.) and were employed in companies from different industries, of different sizes, operating in the province of Lodz minimum of three years. Thus, the group of respondents comprised both young people (but with more than 2-year experience), middle-aged and elderly of both sexes, working for small, medium and also large commercial companies (including public companies listed on the Stock Exchange) having their seat in Lodz, Aleksandrow Lodzki, Konstantynow Lodzki, Zgierz, Pabianice, Lask, operating in various industries such as construction, textile, metallurgy, heating technology, hydraulics, clothing, furniture, beverages etc. There were owners, CEOs, CFOs and chief accountants with economic university education or managerial trainings (including MBA, Chartered Accountant, a doctorate in economics).

The gathered data included 36 interviews (recorded using the tape recorder) complemented with notes reflecting non-verbal reactions of the respondents. 


\section{Results}

The presentation of the results has been divided into two parts giving response to research questions. Hence, first part describes interviewees' beliefs, opinions, remarks on a manner in which they made their liquidity-related decisions that have arisen before the interview (retrospective approach). Second part concerns their reflections evoked during the interview (induced reflection).

\section{Managers' existing consideration on a manner in which they make liquidity- -related decisions}

For a question on whether the respondents have ever wondered how, under what influence, they made decisions concerning liquidity, three types of responses were identified: disaffirmative, emotional and affirmative with a metareflection ingredient.

First type consisted in "No" responses, sometimes even expressed in a very decisive manner. However, the respondents were trying to add a brief comment or rudimentary explanation. None of them gave a comprehensive justification for the absence of such reflection. For instance the answers were:

No, I've never thought about it (resp. 33, older, M, chairman, resp. 28, older, $\mathrm{M}, \mathrm{CFO}$ ),

I've not been wondering... I think it goes spontaneously (resp. 11, older, M, owner).

As far as second type of reactions is concerned, the interviewees very often revealed their bewilderment or even embarrassment with such a question. Judging by their responses it was not a subject of their previous consideration. Yet, they did not want to admit it. They might have thought that they should have an opinion on that matter and therefore they immediately tried to give an answer by enumerating the factors that, in their opinions, might have affected such decisions. Respondent's 1 answer illustrates such an attitude:

No... err... What influences it...? Learning, being sorry several times... (resp. 1, older, M, owner)

On the other hand, for respondents who admitted to have had such a reflection, it turned out that it concerned mainly economical, financial or business aspects.

Yes. When a transaction is profitable this has a direct impact on the liquidity and the lack of liquidity problems in the long run. (resp. 6, older, M, chairman)

In contrast, a pre-existing consideration about the impact of the decisionmaker's characteristics on liquidity-related decisions was rather fragmented. Respondents did not elaborate on such issues in their statements: 
Nowadays, people are driven by intuition. In many cases, mainly by this... (resp. 12, older, F, owner)

What else... ingrown features learned also count... or intuition... (resp. 22, older, M, chairman)

In addition, [... enjoying the risk, because it is very individual attribute (resp. 24, older, F, chief accountant)

The last type of responses might have suggested that the respondent not only had considered decision-making determinants of liquidity management, but also had had a meta-reflection on its quality and usability. The author of below quoted opinion frankly admitted that such thoughts had not been striking him on regular basis, but in his opinion it was rather positive. $\mathrm{He}$ believed that "having no thoughts" was sometimes better for him because he could thereby protect himself from excessive stress.

I sometimes wonder but... to be honest, it is not that I make comprehensive analysis of "what would be if"... It's not what I do every day. If I did it my stress level would be so high that I could not make it. (resp. 30, M, older, chairman)

Only guiding questions stimulated respondents to recall if they had ever considered the impact of the decision-maker on the choices concerning liquidity. An expression analysis showed that the collectivity divided in roughly equal parts to the group that admitted having such a pre-consideration and those who, despite hints given by the interviewer, consistently argued that they had never thought about it before. Interestingly, people who declared this kind of consideration admitted that it appeared due to some negative circumstances, liquidity problems. One may say that this kind of unpleasant or difficult situations motivated respondents to perceive themselves as a factor having an impact on the liquidity of the company. Below an example of this phenomenon:

Yes ... it's been so many years since I've been here ... when I have blue devils or some doubts, in the family or somewhere, then in the company you also foul up a lot of things. (resp. 11, older, M, owner)

To sum up, the respondents did not have an established attitude of what factors influence their liquidity decisions. If such thoughts ever appeared in their professional life, they were mostly of economical or financial nature. Rarely did they see the impact of a decision-maker on such decisions. However, if such reflection took place, it came to their minds mainly in problematic situations, for example when liquidity was in danger. Still, the precise analysis of the interviewees' utterances suggests that they were more likely to search for the causes of a particular situation rather than have more general reflection on the patterns that occur in solving liquidity troubles. 


\section{Respondents' beliefs about liquidity-related decision-making process indu- ced by the interview}

When it comes to the way in which respondents described their standpoint about determinants that affect company's liquidity, it turned out that most of their attention was focused on financial or economical aspects. First of all, the respondents drew attention to the issues that, according to the theory of finance, directly shape the liquidity, i.e. cash (The clue is to have some money on hand, everything depends on this. resp. 1, older, M, owner), inflow of receivables (We have a very strong policy of cash collection resp. 2, older, F, vice- president, First of all cash collection and refraining from granting trade credit. resp. 24, F , older, chief accountant; We offer discounts to our customers, to induce them to pay earlier" resp. 13, M, older, chairman), inventory (... inventory turnover or negotiation of the stock and buying under contracts. The basis is to buy raw materials for one production cycle only, not to store them. resp. 24, F, older, chief accountant) payment of liabilities (My first question always is "What about our payments? We need to assure our suppliers. resp. 7, M, older, owner, ...financing by delaying payments to our suppliers resp. 30, M, older, chairman), loans ([ ... I and, depending on that I take action... I decide whether to make use of credit. These are mainly such decisions... resp. 33, M, older, president), taxes (There are also technical things like paying taxes etc., You must pay in strict time limits. resp. 17, M, younger, CFO) and the current data and ratios (It depends on all liquidity ratios, then you compare these data with the standards for the industry. resp. 28, M, older, CFO).

In addition, respondents also mentioned some strategic aspects, inter alia swiftness of operation (Efficient and fast work. I have to watch over a day and every minute of the day. resp. 1, M, older, owner), company reputation (All the time you need to take care of your image. resp. 36, F, older, chairman ), diversification of activities and customers (I deeply appreciate the fact that we work with a large group of customers. We do not have a customer who has more than $5 \%$ of our sales and this is a huge success. resp. 2, F, older, vice chairman) or investments (...the second thing is that the company is worse than a lover. The idea is that the company needs a lot of money on development, investments, to catch up with different technologies. And relatively low profitability is always a problem. You have to choose whether to earmark the money for current needs or to invest in something that will bring value in the future. resp. 20, M, older, owner).

In their statements also appeared such issues as total economic situation (Well... first of all it is general trend on the market resp. 17, younger, M, CFO; An important factor in decision-making is what is happening in the economic 
environment. resp. 32, M, younger, CFO), branch of industry (... What is the future of a sector, whether something need to be changed, or you need to reorientate somehow... resp. 15, F, younger, co-owner), the sector (Third thing is sector. Whether it is rather a retail sector or, let's call it, receivable-like, with deferred payment. resp. 26, M, younger, CFO), but also knowledge about the market, customers, competition (Well, but for sure... knowledge of the company we cooperate with. resp. $12 \mathrm{~K}$, the older, owner, What is the market demand for certain products that we sell, whether we have a new product we can introduce and compete with others, because others have worse products, or our competition is not so strong... resp. 34, M, older, owner).

The respondents also emphasized that time is a very important factor in their decision-making process. Some of them even regarded it as the most important determinant of their decisions (First of all it's time, I always see to the dates when the expenses must be done. This is the most important factor... When we have cash inflows and outflows. This is the factor that determines all actions, in all respects. resp. 26, $\mathrm{M}$, younger, $\mathrm{CFO}$ ).

In conclusion, the respondents enumerated the most important factors of economic and financial nature that could exert an influence on decisions related to liquidity. Moreover, they did not confine themselves only to those which, by financial science, were considered to be direct determinants of current liquidity (inventories, receivables, liabilities, cash). They expanded their view by the role of competition, market situation, reputation etc. It seems, therefore, that from economical and financial perspective, they had quite a broad notion of factors that might influence their liquidity-related decisions.

As for determinants associated with decision-maker, relevant findings have been aggregated in the following areas:

- what factors that inhere in decision-maker, influenced liquidity choices made by the respondents,

- how significant this impact was,

- whether the respondents were trying to control this influence,

- how they evaluated such an impact (positively or negatively).

In reference to the factors connected with decision-maker, the respondents perceived as particularly important experience and intuition (by some of them also called "sense" or "spontaneity"). Adequate examples below:

These are especially wisdom and experience. Financial textbook knowledge is not so important (resp. 10, M, older, owner)

Decisions are not based only on the liquidity ratios' analysis but on intuition and years of experience. There is no time to analyze the liquidity. (resp. 25, M, older, owner) 
In a small company you need to act intuitively. First of all, you need to have a sense to know what is worth your involvement and what is not. (resp. 7, M, older, owner)

I think it is rather a spontaneity and some experience than any financial knowledge. (resp. 11, M, older, owner).

Furthermore, the interviewees also mentioned some decision-maker's features, which they believed to have had an impact on liquidity decisions. These were:

- common sense: [...] in a company like this, a common sense and simply ground-base handling with this ... and to react to current situations (resp. 33, M, older, chairman);

- human nature (attitude towards money, weaknesses, limitations): I think...first of all it's the nature of a man. I know people, maybe they are not in majority, tight-fisted people... It is human mentality. When he has to spend some money he is becoming sick. (resp. 10, M, older, owner);

- naivety, gullibility: I was naive, I was promised a lot... and then they pulled out. If I could go back in time, I would play out in a different way. While doing business you have to assume that people cheat. You do not call it 'cheating' then but you say that someone just 'took the advantage of the situation'. So it is important what kind of person I am. It affects company's standing and its liquidity. I'm too gullible... (resp. 30, M, older, chairman);

- being unsystematic, lack of diligence: My lack of conscientiousness, lack of regularity. It bothers me. I should require more from myself. But I can afford it because no boss can control me or slap me down for this. Of course I have a strong motivation to avoid errors. On the other hand, no whipping post exists to make me do something... check 5 times, or if I make a mistake I'll be fired. (resp. 3, F, older, owner);

- carelessness: I would prefer to spend all the money for some superfluous gadgets. I behave like a kid. When something cool appears on the market, I'd like to have it. (resp. 25, M, older, owner);

- rigidity, being resistant to external pressure: It seems to me that the way of making decisions, the nature of these decisions is highly dependent on the personality, on psyche, on some human's hardness. Like in this proverb: when you have a soft heart, then you need to have a hard ass. (resp. 14, $\mathrm{M}$, older, owner)

- having strong motivation when things complicate and avoiding the routine: I am such kind of a person and I have such a personality that diffcult situations stimulate me. It has a very big impact on how I act, 
how I manage and what decisions I make. When everything goes well I'm falling into stagnation, in a routine which I'm afraid of. I do not fear any troubles. (resp. 31, F, older, chairman)

- ability to stay calm, stress resistance, clear-mindedness: ... what all the candidates for a job write in their $C V s$ - the ability to cope with stress ... which means to stay calm, have a common sense and keep your mind clear... (resp. 28, M , older, CFO)

- perseverance, consistency and self-discipline: Perseverance has also a huge impact. In business if someone does not have perseverance he won't make it. There are different situations, some are better, some are worse... and this is normal, it's business. What counts is discipline, going straight to the point and not being discouraged by failure. (resp. 19, M, younger, owner);

- prompt decision-making: It happens every day. For example, signing a contract... somebody would shilly-shally for 2 weeks, rethink 5 times, ask 10 lawyers and he would not do that in the end. And I am fast decisionmaker. My decisions are not always good, but that's the way it is. (resp. 19, $\mathrm{M}$, younger, owner).

It needs stressing that the respondents were talking not only about their strengths (common sense, perseverance, determination, tenacity) but also about weaknesses (gullibility). However, they meant mainly personal qualities. None of them did refer to some specific characteristics typical for human's mind functioning. Apparently, the respondents did not have knowledge about this kind of phenomena. Therefore, they could not express their opinions on their role in decision-making, including the financial liquidity sphere.

As regards opinions on the importance of factors associated with the decision-maker while taking liquidity decisions, they varied. Some interviewees believed that the individual attributes of the decision maker did not have any significance for the quality of the final decision.

No, no, no. My whim has nothing to do with it. There's neither randomness nor mood. (resp. 32, M, younger, CFO)

My decisions are never made on the spur of the moment. I can go beyond that. I can find a balance among these things. How am I feeling? No! (resp. 2, F, older, vice president)

There were also more moderate beliefs that certain factors affected decision-making process, while others did not (Yes ... Well, maybe how I'm feeling at the moment has no impact on that, but what kind of a person I am, what way of thinking I have, what forecast is in my head, which solution I choose... it's important... resp. 1, M, older, owner). 
Opinions stating that all above mentioned factors had a significant impact on decisions also eventuated.

I think this has an impact. Sometimes I'm guided by impulse, need of the hour. I'm aware that it may be not so rational, but I give myself the right to make mistakes. (resp. 3, F, older, owner)

Well... for sure. Some personal features are also important. Some people make decisions quickly, they want to take a chance, others prefer to think, to get less but have something for sure. Yes... personal features are very important... They cannot be ignored. No way! (resp. 15, F, younger, co-owner)

As to the question of controlling the impact of human features on decisions made by interviewees, they presented bipolar attitudes. Some of them declared that they tried to control this influence:

From my experience... I don't let any of my moods, troubles at home and so on, penetrate my work. I try terribly to always separate it. I think it has no influence on my decisions. (resp. 26, M, younger, CFO)

While others didn't see such a need at all:

No... It's just me and that's all. The only thing I try to do is to calm down when I know that nothing more can be done. So... I do it to help myself and to survive somehow. (resp. 31, F, older, chairman)

Regarding the respondents' evaluation whether it was good or bad that personal characteristics influenced liquidity-related decisions, the majority of them perceived the impact of mood as rather negative. As far as other aspects are concerned, there was no unequivocal view. To illustrate this, let's quote an opinion given by one of the respondents. In his point of view, the personal features' impact on decisions was not something indisputably negative. It was difficult to predict whether this impact was positive or not, because it constituted an individual management style. And the only aspect to be assessed here was whether certain management style was more or less relevant for the entire organization, and not in terms of "good - bad".

For sure. I think we're burdened with some set of genes, and as a consequence we have some set of features and it is difficult to control them. I think that there's no need to control them, because they create some kind of a style. Our knowledge and what kind of people we are, form our management style. The only question is whether this style, in a certain environment, is more appropriate. I separate it completely. I'm like a machine. I can say that. I was given a task and I have to fulfil it. (resp. 4, F, older, chairman)

The above statements and reactions proved that respondents stimulated by the course of interview recognized the impact of decision-maker's personal features on choices connected with liquidity. Moreover, the interviewees widely 
perceived such determinants as meaningful. The list of factors mentioned by the respondents comprised: experience, intuition, character (defined as the attitude towards money), common sense, faith in one's own luck, risk aversion, perseverance, the ability to stay calm in difficult situations. What seems intriguing, they discredited a frame of mind as a determinant of their decisions. When it comes to the question whether respondents tried to reduce decisionmaker's individual features' influence on their decisions, the answers were double-sided. Some admitted to have made attempts to minimize such an impact, others presented an opinion that controlling their human traits was not necessary. They were not able to unambiguously judge whether the occurrence of such an effect was beneficial or not.

\section{Conclusions}

The analysis of the interviews revealed that respondents, in the course of their career, devoted little attention to the problem of determinants influencing decisions concerning liquidity of companies for which they worked. Some respondents, however, seemed to be embarrassed with a lack of such consideration, what may denote that they did not consider this beneficial. Nevertheless, this requires further analysis, because such a reaction could also result from other reasons. The question about what kind of determinants exerted an influence on their decisions had not been a subject of their professional reflection. It was not a crucial problem to be solved from their point of view. If such a consideration ever emerged it appeared mostly in alarming situations or during some interim liquidity crisis. So it was not a general deliberation but it concerned specific situations. Even then, respondents did not take into account the role of decision-maker, but financial, economical or legal factors. Their opinions focused primarily on the subject (not the person acting) of decisions, which is liquidity itself, and certain circumstances affecting it such as payment terms, cash, market trends, industry development etc.

The fact that respondents connoted mainly financial associations does not seem surprising. Still, interviewees' answers provided evidence that professionals were - in a way - 'closed' for other possible determinants of their choices, especially including those concerning decision-maker. Only the interview itself induced respondents to recognize the importance of the subject of choices or even to consider it significant.

It should be also highlighted, that factors enumerated by the respondents did not relate to mechanisms identified by behavioural economics or behavioural finance such as availability heuristics [Kahneman, Tversky 1982], anchoring heuristics [Remus, Kotteman 1995], illusion of control [Langer 
1975], framing effect [Tversky, Kahneman 1981], locus of control [Thomas, Sorrensen, Eby 2006], conjunction effect [Mellers, Hertwig, Kahneman 2001] and many others, which are an essence of these newly emerging domains. This means that respondents were not aware of the existence of such phenomena. Their remarks touched upon some general 'human-related' issues like experience, common sense, intuition and so on. As a result, being unfamiliar with "decision traps" makes managers prone to cognitive biases that may affect their decisions. Moreover, lack of awareness that such mechanisms occur, entrails lack of necessity to extend the knowledge in this field. It is hard to imagine that someone wants to learn about the things he did not know they existed.

In view of the above, the thesis put at the beginning of that paper, stating that a level of absorption of scientific discoveries by practitioners (managers, directors, headset) is still low, seems to validate. Thus, making managers informed about the existence of certain "human mechanisms" and extending their professional knowledge through trainings, courses or seminars would bring many benefits and improve the quality of their decisions.

\section{Bibliography}

Bazerman M.H. (1994), Judgement In Managerial Decision Making, New York: John Wiley \& Sons Inc.

Jones B.D. (1999), Bounded Rationality, “Annual Review”, 2, pp. 297-321.

Kahneman D. (1991), Judgment and Decision Making: A Personal View, "Psychological Science", Vol. 2, No. 3.

Kahneman D., Tversky A. (1982), Judgement under uncertainty: Heuristics and biases, Cambridge: Cambridge University Press.

Korzeniowska D. (2011), Psychological Factors' Influence on Liquidity Decision Making Process in Times of Economic Instability, Acta Universistatis Lodziensis, "Folia Oeconomica", 247, pp. 289-306.

Korzeniowska D. (2013), Decision Traps' Impact on Liquidity Management in Enterprises, in: D. Adrianowski, K. Patora, J. Sikorski ed., Finance, Accounting and Management: Poland, Europe, World 2020, Lodz: University of Lodz Publishing House, pp. 117-125.

Langer E. (1975), The illusion of control, "Journal of Personality and Social Psychology", 32.

Mellers B., Hertwig R., Kahneman D. (2001), Do Frequency Representations Eliminate Conjunction Effects?, "Psychological Science", Vol. 12, No. 4. 
Remus W., Kottemann J. (1995), Anchor-and-adjustment behaviour in a dynamic decision environment, Elsevier Science, Decision Support Systems 15.

Thomas W.H.NG., Sorensen K.L., Eby L.T. (2006), Locus of control: meta-analysis, "Journal of Organizational Behavior", September, 27.

Tversky A., Kahneman D. (1981), The framing of decision and the psychology of choice, "Science", Vol. 211, No. 4481.

Tyszka T. (2000), Psychological Traps in Assessing and Decision Making, Gdansk: GWP.

Tyszka T. (2010), Decisions: Psychological and economical perspective, Warsaw: SCHOLAR. 